Polymer Journal Vol. 10, No. 1, pp. 117-119 (1978)

NOTE

\title{
Imidazolylmethylation of Poly(vinyl alcohol) by Chloromethylimidazole
}

\author{
Masaaki KIDA* and Hidehiko NAKANo \\ Department of Applied Chemistry, Himeji Institute of \\ Technology, Himeji 671-22, Japan.
}

(Received July 25, 1977)

KEY WORDS Poly(vinyl alcohol) Imidazolylmethylation / Chloromethylimidazole / ${ }^{13} \mathrm{C}$ NMR /

Recently, imidazole-containing polymers have been investigated as functional polymers. Synthesis of such polymers by introducing imidazole groups to the side chains of host polymers may be preferable to the procedure of copolymerization of imidazole-containing monomers. This is because it is possible to obtain polymers of various imidazole contents without altering the degree of polymerization. It was tried to introduce an imidazole group into the neutral water-soluble polymer poly(vinyl alcohol) (PVA), although the Williamson reaction of 4(5)chloromethylimidazole with sodium alkoxide was reported not to be successful. ${ }^{1}$ This paper describes the method to obtain imidazolylmethylated PVA as follows. 4(5)-chloromethylimidazole was allowed to react with PVA in the aprotic polar solvent $N, N$-dimethylformamide (DMF).

\section{EXPERIMENTAL}

\section{Materials}

PVA (DP 2000) and PVA (DP 500) were purchased from Wako Pure Chemical Industries, Ltd., and from Nakarai Chemicals, Ltd., respectively. Their molecular weights, measured by the viscometric method, ${ }^{2}$ were 85,300 and 22,600 . 4(5)Chloromethylimidazole hydrochloride was prepared according to the method of Turner, et al. ${ }^{1}$

* Present Address: Department of Organic Synthesis, Faculty of Engineering, Kyushu University, Fukuoka 812, Japan.
4(5)-Imidazolylmethylation of PVA

PVA was dissolved in DMF at the concentration of $1 \%$ with the aid of heat. 4(5)Chloromethylimidazole hydrochloride was added to the solution; the molar ratios of this to the hydroxyl group of PVA ranged from 0.5 to 5 . The mixture was heated at $85^{\circ} \mathrm{C}$ in a sealed tube under $\mathrm{N}_{2}$. The reaction product was poured into a Visking cellulose tube (size 24/32) and dialized against water for $48 \mathrm{hr}$. From the clear solution, a white or pale yellow spongy product was obtained by freeze-drying. The extent of substitution was calculated from the nitrogen content measured by a Yanaco CHN-corder (type MT-2).

Measurement of ${ }^{13} \mathrm{C}$-NMR Spectra

${ }^{13} \mathrm{C}-\mathrm{NMR}$ spectra were acquired on a Japan Electron Optics Laboratory JNM-FX 60 spectrometer, which is of Fourier transform type, operating at $15.04 \mathrm{MHz}$. The spectra was measured by $\pi / 4$ pulses with complete proton decoupling; free induction decay signals of the repeating pulses were accumulated and Fourier transformed by the built-in computer (JEC980A).

\section{RESULTS AND DISCUSSION}

\section{4(5)-Imidazolylmethylation of PVA}

Table I shows the extent of substitution when PVA and 4(5)-chloromethylimidazole hydrochloride were heated at $85^{\circ} \mathrm{C}$ for 1 to 5 days in DMF. It was reported that an attempt to prepare ethers by treating the 4(5)-chloromethyl- 


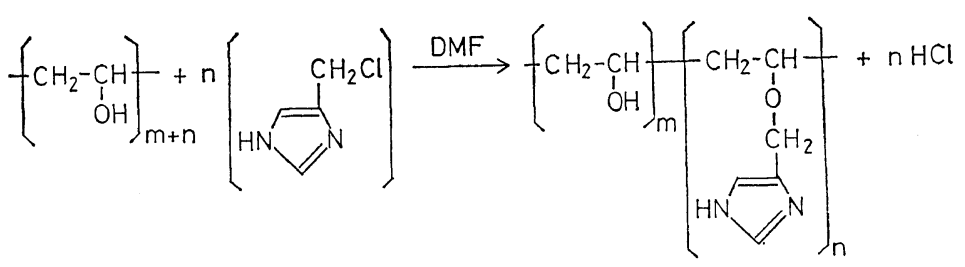

Figure 1. Schematic representation of imidazolylmethylation of PVA.

Table I. Extent of imidazolylmethylation ${ }^{a}$

\begin{tabular}{ccccc}
$\begin{array}{c}\text { Sample } \\
\text { no. }\end{array}$ & DP & $\begin{array}{c}\text { Moles of } \\
\text { chloro- } \\
\text { methyl- } \\
\text { imidazole } \\
\text { added, per } \\
\text { OH of } \\
\text { PVA }\end{array}$ & $\begin{array}{c}\text { Reaction } \\
\text { time, } \\
\text { day }\end{array}$ & $\begin{array}{c}\text { Extent of } \\
\text { substi- } \\
\text { tution, } \\
\%\end{array}$ \\
\hline 1 & \multicolumn{5}{c}{$\begin{array}{c}\% \\
2\end{array}$} & 2000 & 1 & 1 & 19.0 \\
3 & 2000 & 1 & 2 & 28.2 \\
4 & 2000 & 1 & 3 & 31.9 \\
5 & 2000 & 1 & 4 & 36.4 \\
6 & 2000 & 0.5 & 5 & 37.7 \\
7 & 2000 & 5 & 5 & 18.3 \\
8 & 500 & 1 & 1 & 51.4 \\
9 & 500 & 5 & 5 & 21.5 \\
& & 1 & 57.0
\end{tabular}

a The concentration of PVA in DMF was $1 \%$ and the reaction temperature was $85^{\circ} \mathrm{C}$.

imidazole hydrochloride with sodium alkoxides was not successful and only resinous substances resulted. ${ }^{1}$ In our experiment, it seems that an ether bond was formed with the aid of DMF functioning as a weak base, as shown in Figure 1. When a similar aprotic polar solvent, dimethyl sulfoxide, was used, a dark brown precipitate was obtained; this was insoluble in water and in every organic solvent tested.

\section{${ }^{13}$ C NMR Spectroscopy}

${ }^{13} \mathrm{C}$ NMR spectra of 4(5)-imidazolylmethyl PVA, PVA and 4(5)-hydroxymethylimidazole hydrochloride are shown in Figure 2; the assignment of each signal is indicated in the figure. In the case of 4(5)-hydroxymethylimidazole (A), the signal at $54.6 \mathrm{ppm}$ was assigned to the methylene carbon and signals at 117.7, 133.5, and $135.0 \mathrm{ppm}$ were assigned to the carbons of imidazole ring. The methylene carbon of PVA shows a broad peak at $45.4 \mathrm{ppm}$. The signals assigned to the methine carbon of PVA were
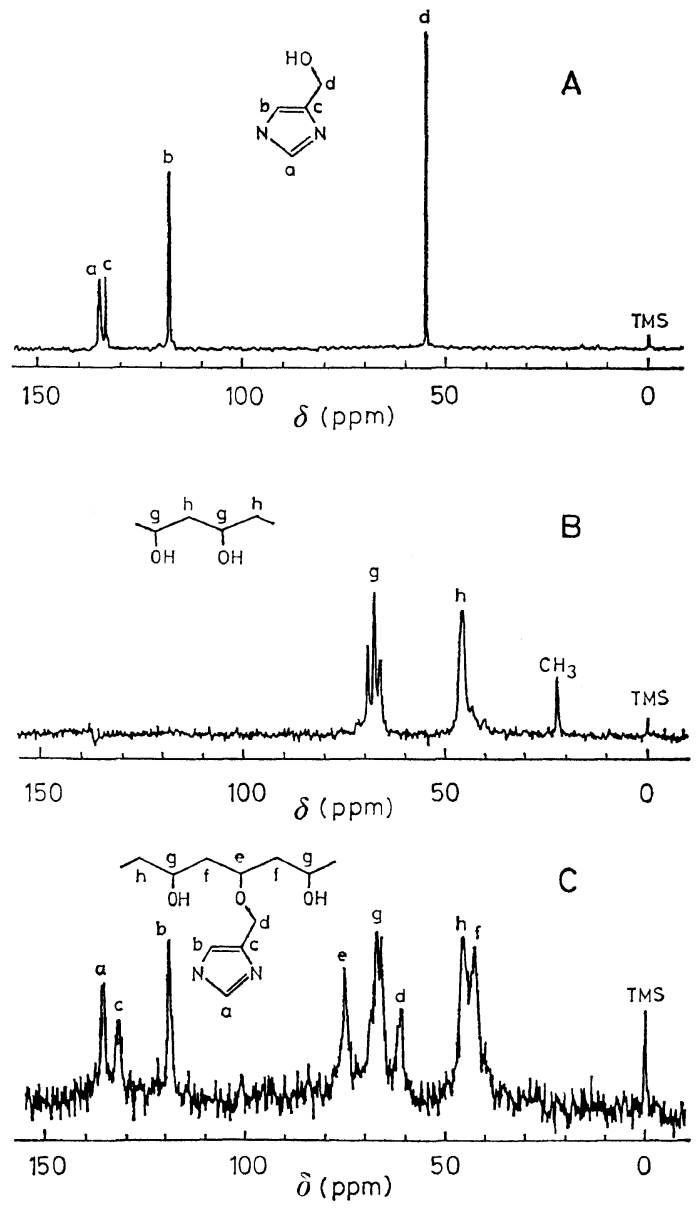

Figure 2. ${ }^{13} \mathrm{C}$ NMR spectra of imidazolylmethylated PVA and related compounds. Samples were as follows: (A) hydroxymethylimidazole hydrochloride, $20 \%$; (B) PVA (DP 500), $25 \%$; (C) imidazolylmethyl PVA (Sample No. 9 in Table I), $10 \%$ (each was in $\mathrm{D}_{2} \mathrm{O}$ ). Numbers of pulses accumulated were 4,000(A), 3,000 (B), and 15,000 (C). 
split into three peaks $(69.1,67.5,66.2 \mathrm{ppm})$ owing to microtacticity; these peaks were assigned by Inoue, et al., ${ }^{3}$ to $m m, m r$, and $r r$ triads with increasing field strength. The signal corresponding to methyl carbon $(22.0 \mathrm{ppm})$ is probably due to an unsaponified acetyl group; the ratio of its peak area to that of methylene carbon was about 13\%. Even though, in the case of ${ }^{13} \mathrm{C}$ NMR spectra, the peak area is not accurately proportional to the number of the atoms, this value coincides with the saponification value specified by the maker (84-89\%). The signal corresponding to the carbonyl carbon will appear at about $170 \mathrm{ppm}$, which is out of the measured range. Judging from the spectra of poly(vinyl acetate), ${ }^{3}$ the signals attributed to the methine carbons of unsaponified and saponified parts overlapped, and the trailing of the peak of methylene carbon at about $41-43 \mathrm{ppm}$ is probably due to the methylene carbon of the unsaponified part. In the spectrum of the reaction product $(\mathrm{C})$, the signals corresponding to the carbons of imidazole ring $(118.4,131.4$, $135.2 \mathrm{ppm}$ ), and similar peaks corresponding to the signals of PVA $(45.5,65.7,66.9,68.3 \mathrm{ppm})$ are seen. In addition to these signals, three peaks at $74.9,61.2$, and $42.3 \mathrm{ppm}$ appeared. By the empirical rule that the $\delta$ value of ethereal $\alpha$-carbon is higher by about $5 \mathrm{ppm}$ compared with that of corresponding alcoholic $\alpha$-carbon and the $\delta$ value of ethereal $\beta$-carbon is lower by about $4 \mathrm{ppm},{ }^{4}$ these signals were assigned as follows. The signal at $61.2 \mathrm{ppm}$ corresponded to the methylene carbon connecting the oxygen atom and the imidazole ring. The signals at 74.9 and $42.3 \mathrm{ppm}$ were assigned to the methine carbon adjacent to ethereal oxygen and to the neighboring methylene carbons, respectively. These assignments are consistent with the structure assumed in Figure 1.

\section{REFERENCES}

1. R. A. Turner, C. F. Huebner, and C. R. Scholz, J. Am. Chem. Soc., 71, 2801 (1949).

2. A. Nakajima, Kobunshi Kagaku (Chem. High Polymers), 6, 460 (1949).

3. Y. Inoue, R. Chûjô, A. Nishioka, S. Nozakura, and H. Iimuro, Polym. J., 4, 244 (1973).

4. G. C. Levy and G. L. Nelson, "Carbon-13 Nuclear Magnetic Resonance for Organic Chemists," Wiley-Interscience, New York, N.Y., 1972. 